\title{
Results of a mass casualty incident simulation in an undergraduate nursing program
}

\author{
Nora Zinan , Denise Puia, Terry Kinsley \\ University of Saint Joseph, West Hartford, Connecticut, United States
}

Received: July 27, 2015

Accepted: August 30, 2015

Online Published: September 22, 2015

DOI: $10.5430 /$ jnep.v5n $12 \mathrm{p} 71$

URL: http://dx.doi.org/10.5430/jnep.v5n12p71

\begin{abstract}
Background: Nurses in collaboration with fire rescuers, emergency medical technicians (EMTs), and doctors are often called to be first responders to world-wide disasters ranging from terrorist attacks to catastrophic weather events. The American Association of Colleges of Nursing has established the need for disaster-preparedness education in baccalaureate nursing programs. Limited research has been conducted about the impact of utilizing simulation as an educational tool to prepare nursing students for disaster response. This paper presents the results of a simulation of a mass casualty incident utilizing low-fidelity and static manikins, as well as actors to play the role of victims, family members and news personnel.

Methods: One hundred and seven students from traditional and accelerated second-degree programs participated in a simulation in the roles of victims as well as providers. A quasi-experimental pre- and post-test design was used to assess students' selfperceptions.

Results: Statistically significant improvement in self-perceived knowledge, attitudes and skills was seen. Students who participated as victims or providers reported similar improvements.

Conclusions: Well-designed and concise mass casualty incident simulation is a valuable educational tool that can be easily incorporated into nursing curricula, with students undertaking the role of either a victim or a provider.
\end{abstract}

Key Words: Accelerated second degree nursing students, Baccalaureate nursing education, Disaster response simulation, Mass casualty incident, Mass casualty incidents simulation, Nursing simulation, Nursing students

\section{INTRODUCTION}

Each year disasters occur world-wide ranging from terrorist attacks to catastrophic weather events. These mass casualty incidents (MCI) require emergency health care teams to treat large numbers of injured victims. Nurses in collaboration with fire rescuers, emergency medical technicians (EMTs), and doctors are often called to be first responders. Nurses have significantly contributed to disaster response efforts, ${ }^{[1]}$ and nurses who have a greater knowledge of disaster response or who have had disaster training are more willing to respond to mass casualties. ${ }^{[2,3]}$
The American Association of Colleges of Nurses (AACN) establishes the need for disaster-preparedness education in baccalaureate nursing programs in Essential VII of the Essentials of Baccalaureate Education for Professional Nursing Practice. It states "the baccalaureate education program prepares the graduate nurse to use clinical judgment and decision-making skills in appropriate, timely, nursing care during disaster, mass casualty, and other emergency situations". ${ }^{[4]}$ A national survey of student nurses indicated a general lack of emergency preparedness. ${ }^{[5]}$

The International Council of Nurses (ICN) has identified 10

\footnotetext{
*Correspondence: Nora Zinan; Email: nzinan@usj.edu; Address: University of Saint Joseph, 1678 Asylum Ave, West Hartford, Connecticut 06117, United States.
}

Published by Sciedu Press 
competencies in managing disasters. ${ }^{[6]}$ They are presented in Table 1, along with the teaching strategies used in this study to address them. Benner's Novice to Expert Model guided the development and implementation of the simulation. ${ }^{[7]}$ A goal of this study was to advance students along the continuum from their current level of novice.

Table 1. ICN framework of the disaster nursing competencies

\begin{tabular}{llll}
\hline ICN Competency & \multicolumn{2}{l}{ Teaching Strategy } \\
\hline 1) & Risk Reduction, Disease Prevention and Health Promotion & 1) & Didactic \\
2) & Policy Development and Planning & 2) & Didactic, debriefing \\
3) & Ethical Practice, Legal Practice and Accountability & 3) & Didactic, simulation, debriefing \\
4) & Communication and Information Sharing & 4) & Didactic, simulation, debriefing \\
5) & Education and Preparedness & 5) & Didactic \\
6) & Care of Communities & 6) & Didactic \\
7) & Care of Individuals and Families & 7) & Didactic, simulation, debriefing \\
8) & Psychological Care & 8) & Didactic, simulation, debriefing \\
9) & Care of Vulnerable Populations (Special Needs Populations) & 9) Didactic, simulation, debriefing \\
10) & Long-term Care Needs & 10) & Didactic \\
\hline
\end{tabular}

Since disasters are unpredictable and widely dispersed geographically, the opportunity for a student to observe the triage and care of disaster victims is slim. Furthermore, in an actual disaster, the environment is chaotic, the resources are limited, and many people have life threatening injuries which create a poor learning environment. Simulation can provide a safe learning environment while recreating the chaos, multiple casualties and the severity gradient of injuries found in a MCI.

Much has been written about the process of developing disaster preparedness education activities for nursing curricula. ${ }^{[8-10]}$ Yet limited research has been conducted on the effects of that education. Additionally, the content, amount and methods of education varied. Atack, and colleagues ${ }^{[11]}$ conducted a study of 36 undergraduate students from various health disciplines who participated in a 5-hour simulation exercise involving students, experienced emergency professionals and several hundred participants. Much of the learning consisted of online activities prior to participating in a live disaster simulation involving hundreds of people. Results revealed a significant increase in perceived levels of disaster preparedness competency including being able to categorize different disasters, prioritize and share information, describe safety measures, and identify roles. In a similar multidisciplinary study, Hutchinson and colleagues ${ }^{[12]}$ educated 81 undergraduate nursing, psychology and public health students utilizing a disaster simulation of a campus explosion. Results indicated an increase in knowledge and ability to triage victims.

Three studies incorporated low and high fidelity mannequins into the simulation. ${ }^{[13-15]}$ Morrison and Catanzaro created a scenario in which 79 senior nursing students participated in a simulation using a high fidelity manikin as a casualty. Students reported that using simulation as a learning activity was appropriate ${ }^{[13]}$ Shannon found similar results in a study of 63 senior level baccalaureate nursing students who were surveyed following a low fidelity MCI simulation. ${ }^{[14]}$ The majority of students found the experience to be positive. Kaplan and colleagues used low fidelity simulation with 90 senior nursing students within the simulation lab. Students reported the simulation increased their knowledge and confidence in emergency preparedness. ${ }^{[15]}$

Two related studies used simulation to practice certain emergency skills. ${ }^{[16,17]}$ Pang and colleagues conducted a pilot study with 150 Chinese undergraduate nursing students to develop disaster nursing competencies. The students participated in 60 hours of classes, of which only five hours was didactic content. The majority of class time was spent on active learning including small group activities and simulation. Analysis of pre- and post-test surveys revealed an increase in students' knowledge and confidence to respond to disasters. ${ }^{[16]}$ Chan and colleagues replicated the pilot study with 150 students from 44 schools. The results indicated a significant increase in disaster competencies, willingness to aid in disaster response, and a perceived ability to perform competently under supervision. ${ }^{[17]}$

Simulation has also been used through virtual reality experiences and tabletop exercises. ${ }^{[18,19]}$ Farra and colleagues conducted a study of 47 second year associate degree nursing students using web-based teaching and virtual reality simulation (VRS). The VRS group was found to have significant knowledge retention. ${ }^{[18]}$ Landry and Stockton also used multiple methods of education including a 3-hour didactic course with web-based training, an 8-hour online emergency 
preparedness curriculum, and a disaster preparedness tabletop simulation exercise. Thirty nursing students evaluated the program. The results indicated that the hands-on practice was the preferred learning method. ${ }^{[19]}$

Only two published studies utilized role-playing within the nursing lab environment in the disaster simulation; however all students involved played the part of provider. ${ }^{[14,15]}$ This pilot study evaluates the effectiveness of MCI simulation that incorporates low-fidelity and static manikins, and role-playing, with some students acting as a victim, family member or news personnel. The objectives focus on training students about communicating within the incident command structure, triage protocols, roles of team members and nursing care needed during a MCI. It was believed that following the simulation, students would feel more skilled and willing to respond to a MCI, understand team roles, and be able to provide first aid and emotional care. It was expected that they would perform their duties in a chaotic environment, and that learning would occur even if they participated in the simulation as a victim or a provider.

The following research questions were addressed:

(1) Do students' self-perceived knowledge of participating in and responding to a disaster increase significantly when utilizing simulation to teach about disaster response?

(2) Will students report that they are more willing to respond to a disaster because of the training they've received?

(3) Is there a difference in self-perceived knowledge and abilities between students who participate as victims versus care providers?

\section{METHOD}

\subsection{Research design}

A quasi-experimental pre-/post-test design was used to assess the students' willingness to respond to a disaster as well as their self-perceived knowledge and ability to function as a part of the healthcare team. The study received Institutional Review Board approval from the University. Students were informed that completion of the anonymous survey was voluntary and that return of the survey implied consent to participate.

\subsection{Sample}

A convenience sample of traditional and accelerated second degree (ASD) baccalaureate nursing students from a private women's college in New England participated in the MCI simulation during their Community Nursing class ( $\mathrm{N}=$ 107). The simulation was conducted in three separate groups which corresponded to their respective course sections, over the period of a year (2014-2015). Traditional students participated during the final semester of the senior year. The ASD students participated during the third semester of their education. In each section, approximately 14 students ( $N$ $=40$ ) were assigned and prepped to play the role of a victim, depending on the size of the class. The ASD class was smaller and utilized fewer victims $(n=11)$. Prior health care experience was used as the inclusion criteria to participate as a victim. However, students were allowed to decline that role and selection proceeded until the required number of victims was obtained. The remaining 67 students were designated as care providers, triage nurse and secondary triage nurse, team leader and logistics coordinator.

\subsection{Procedure}

Prior to the simulation, all students received 1-hour didactic content from their professors, who were also the researchers. The content related to disaster prevention, planning and response, and mitigation. Students also completed the presimulation survey. The nursing lab was set up as the lobby of an assisted living facility, where student nurses were conducting a fictional "Blood Pressure Clinic". The Lab Director, who also acted as a researcher, designed the lab setup and informed students about the scenario of a fire at the facility that involved multiple injuries. Low fidelity and static manikins, and live actors were attired using make-up and costumes. Victims included elderly males and females with burn and smoke-inhalation injuries, comorbidities, and varying emotional responses. Some victims had already expired or were near to expiring. An 8-year old visitor, a 24-year old staff member and a 50-year old family member were among the victims. A news reporter circulated during the scene.

A loud siren sounded throughout the scenario. The class professor acted as the Incident Commander and assigned a student to the role of the Team Leader amidst the chaos, who then assigned the remaining roles. The Incident Command structure used in this scenario was adapted from that of the US Department of Labor, ${ }^{[20]}$ and is presented in Figure 1.

The triage nurses were challenged with the tasks of triaging and tagging patients according to the Simple Triage and Rapid Treatment (START) model developed by the Newport Beach Fire Department in the 1980's. ${ }^{[21]}$ The care providers were expected to provide nursing care and first aid as their assessments and triage dictated, work as a member of a team, respond to victims in emotional distress and maintain safety in the immediate area with a backdrop of chaos. The scenario was run for 20 minutes and debriefed. Debriefing is a period of time devoted to reflecting about the scenario, including its positive aspects and improvements that could be made. It is 
recognized as an essential step in simulation education and allows students to identify patterns and alternatives, and analyze perceptions and consequences of actions. ${ }^{[22]}$ Following the debriefing, the simulation was run and debriefed a second time. Team Leader roles were rotated to another student for the second running of the simulation. The goal of repeating the scenario was to allow students to learn from mistakes and make corrections in order advance cognitive, affective and psychomotor learning. The post-simulation survey was administered immediately following the second simulation and debriefing.

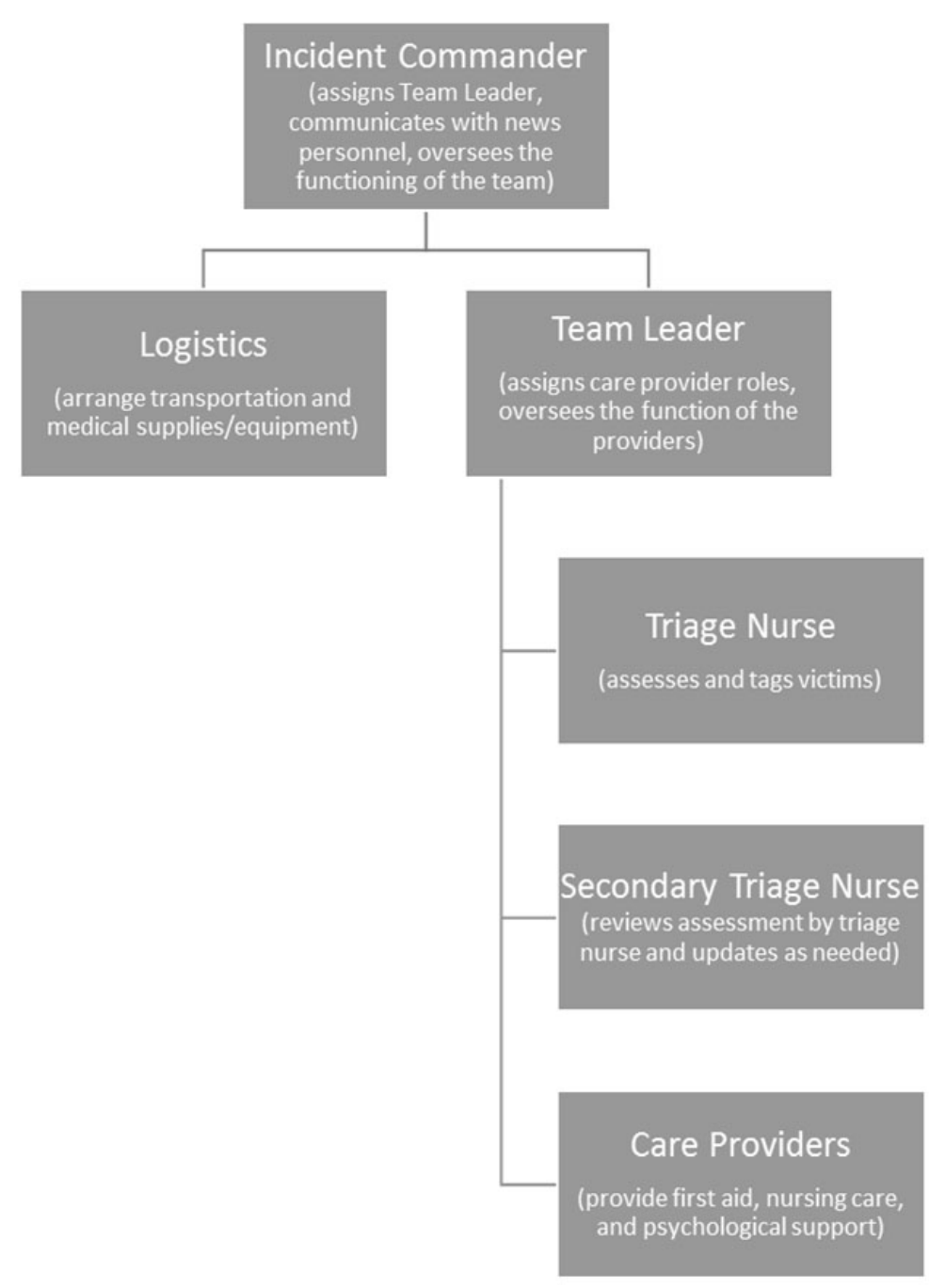

Figure 1. Simulation incident command structure

\subsection{Instrument}

The survey instrument was designed by the investigators based on the ICN framework and the educational objectives. It had good internal consistency (Cronbach alpha $=0.87$ ). Demographic data included age, gender and prior healthcare and mass casualty experience. Nine questions reflecting the educational objectives were also asked and responses were based on a 5-point Likert scale ( $5=$ strongly agree, $4=$ agree, 3 = no opinion, 2 = disagree, 1 = strongly disagree). A retrospective pre- and post-test survey was administered 1 week after the simulation to assess willingness to respond to a MCI and confidence as a nurse (see Table 2).

\subsection{Data analysis}

The data were coded to allow for data entry and checked for errors. Analysis was performed using SPSS software for Windows, Version 18. SPSS managed missing data such that responses for that individual were eliminated on the item analyzed. Subsequent frequencies ranged from an $\mathrm{N}$ of 70-107.

Descriptive statistics were used to illustrate the participants' characteristics. Independent $t$-tests and cross-tabs were used 
to compare the traditional and ASD students, and the victims and providers, with regards to four covariables: age, prior experience in a MCI simulation, prior experience in a MCI event, and prior healthcare experience. Paired t-tests analyzed responses to nine variables on the pre- and post-test surveys, as well as the two questions posed 1-week after the simulation. A one-way repeated-measures ANOVA was used to analyze the nine variables with the victim and provider roles.

\section{Results}

\subsection{Sample}

A total of 110 baccalaureate nursing students participated in the MCI simulations, two of which were men (see Ta- ble 3). Three students did not complete the post-test survey resulting in a sample of 107 students. ASD students comprised $17.8 \%$ of the group. Mean ages differed significantly between the Traditional and ASD students $(M=22.5$ and 29.7 respectively, $t=3.9, \mathrm{df}=15.2, p=.001$ two-tailed), but not between the victims and providers $(\mathrm{M}=23.14$ and 23.9 respectively, $t=-.85$, df $=95.1, p=.39)$. The majority of students $(69.2 \%)$ reported having prior healthcare experience, while $17 \%(\mathrm{n}=18)$ reported previously participating in an MCI simulation, and 3\% $(n=3)$ reported prior participation in a MCI event. Traditional and ASD students also differed significantly regarding prior healthcare experience $(p<.05)$, however, victims and providers did not $(p=.826)$.

Table 2. Pre and Post-test survey results

\begin{tabular}{|c|c|c|c|c|}
\hline Item & Mean Pre & Mean Post & df & Sig. \\
\hline I am familiar with mass casualty triage. & 2.19 & 3.02 & 85 & 0.000 \\
\hline I understand the team roles in a mass casualty disaster (ICN 4, 7, 9). & 2.43 & 3.17 & 74 & 0.000 \\
\hline I am able to respond as a care provider during a mass casualty event. & 2.68 & 3.24 & 62 & 0.011 \\
\hline I am able to prioritize the care of victims affected by a mass casualty event. & 2.76 & 3.23 & 61 & 0.153 \\
\hline I am able to provide safe and effective basic first aid during a mass casualty event. & 2.97 & 3.25 & 86 & 0.002 \\
\hline $\begin{array}{l}\text { I am able to identify the ethical issues related to providing care to all victims during } \\
\text { a mass casualty event. }\end{array}$ & 3.01 & 3.24 & 70 & 0.127 \\
\hline $\begin{array}{l}\text { I recognize the limits to my knowledge, skills and authorities related to a mass } \\
\text { casualty event. }\end{array}$ & 3.13 & 3.26 & 91 & 0.000 \\
\hline I am able to assess the safety of self and others during a mass casualty event. & 2.94 & 3.29 & 77 & 0.001 \\
\hline $\begin{array}{l}\text { I am able to recognize the most appropriate health care role for myself during a mass } \\
\text { casualty event. }\end{array}$ & 2.79 & 3.18 & 66 & 0.000 \\
\hline \multicolumn{5}{|l|}{ Retrospective Pre- and Post-test Survey Questions } \\
\hline My willingness to respond as a care provider to a mass casualty event & 2.83 & 3.78 & 108 & 0.000 \\
\hline My confidence in my abilities as a nurse & 2.59 & 3.50 & 108 & 0.000 \\
\hline
\end{tabular}

Table 3. Individual characteristics of students

\begin{tabular}{lllll}
\hline & $\begin{array}{l}\text { Traditional Program } \\
\mathbf{N = 8 8}\end{array}$ & $\begin{array}{l}\text { Accelerated Second Degree } \\
\text { Program (ASD) } \mathbf{N}=\mathbf{1 9}\end{array}$ & $\begin{array}{l}\text { Victim } \\
\mathbf{N = \mathbf { 4 0 }}\end{array}$ & $\begin{array}{l}\text { Provider } \\
\mathbf{N}=\mathbf{6 7}\end{array}$ \\
\hline $\begin{array}{l}\text { Mean Age in years } \\
\text { Ever Participated in MCI Simulation } \\
\text { Yes }\end{array}$ & 22.5 & 29.7 & 23.1 & 23.9 \\
No & $15(17.0)$ & $3(15.8)$ & $8(20.0)$ & $10(14.9)$ \\
Ever Participated in an MCI event & $73(83.0)$ & $12(63.2)$ & $29(72.5)$ & $56(83.5)$ \\
Yes & $3(3.4)$ & & $1(2.5)$ & $2(3.0)$ \\
No & & $0(0.0)$ & $36(90.0)$ & $65(97.0)$ \\
Prior Healthcare Experience & $85(96.6)$ & & $25(62.5)$ & $20(29.9)$ \\
Yes & $65(73.9)$ & $16(100)$ & $12(30.0)$ & $47(70.1)$ \\
No & $23(26.1)$ & $9(47.4)$ & $7(36.8)$ & \\
\hline
\end{tabular}

Note. Data are n (\%) for all participants. Some columns may not equal the number of participants due to missing data. 


\subsection{Survey results}

A significant increase in means was seen in the overall group in seven of the nine items measured on the pre- and posttest surveys (range of significance: $p=.001-.01$ ). Only two items: the ability to prioritize care of victims and the ability to identify ethical issues related to providing care to victims did not show a significant improvement ( $p=.15$ and .07 respectively). However, both victims and providers reported significant improvement in all nine variables $(p<$ .05). Prior healthcare experience had a moderate effect on ability to identify ethical issues, which may explain the result (Wilk's Lambda $=.922, \mathrm{~F}(1,61)=4.81, p<.032$, partial eta squared $=.07)$ and was likely due to the significant difference between traditional and ASD students regarding this factor. The lack of improvement in the ability to prioritize the care of victims is unexplained by the effect of covariables and may be due to factors presented in the Discussion section of this paper. The two questions asked in the retrospective preand post-test survey demonstrated significant increases (see Table 2).

\section{Discussion}

\subsection{Simulation design}

Simulation experiences are designed to reinforce didactic content and provide active learning to improve clinical decision-making, critical thinking, communication and psychomotor skills. ${ }^{[23]}$ In addition to meeting learning objectives, a secondary goal of designing and implementing learning experiences, both in the clinical environment and in simulation activities, is to utilize the strengths of stronger students, and draw out the strengths of quieter students. This strengths-based approach to learning allows students to recognize and utilize their strengths to meet their educational goals. ${ }^{[24]}$ This was a consideration in designing the simulation and selecting students for the various roles. Provider roles were rotated in order to equalize skill-development among the student ${ }^{[25]}$ and minimize potential "friend" bias.

This simulation, including the didactic education portion, addressed all of the competencies identified in the ICN Framework, ${ }^{[6]}$ and was guided by Benner's Novice to Expert Model. ${ }^{[7]}$ While the setup for the simulation was extensive, the duration of the didactic, simulation and debriefing portions only lasted 2 hours. The simulation alone lasted approximately 20 minutes with each enactment and was run twice, followed by debriefing. It differed from other simulations in that it utilized a combination of low-fidelity and static manikins, as well as actors to play the role of victims, family members and news personnel. As mentioned previously, this is a novel approach.

The survey results reflected the students' perceived changes in cognitive, affective and psychomotor learning that is required for participation in simulation. Cognitive elements included the context of an MCI, the understanding of team roles, the criteria used to triage victims and the need for safety assessment. The affective domain included recognition of the ethical issues involved in providing care to a large number of victims, including vulnerable populations, the value of recognizing limits of their abilities and authorities, willingness to respond to a mass casualty event, and confidence in abilities as a nurse. The term authorities was defined by the researchers as the ability to work within the legal limits of your profession. The psychomotor domain included being able to provide first aid as well as respond to the emotional issues of victims and their families.

\subsection{Interpretation of results}

The increase in students' self-perceived knowledge, attitudes and skills was similar to previous reports. ${ }^{[11,12,15]}$ Significant improvement was seen in all learning domains but not all elements of the domain. Two of 11 variables in the pre- and post-test survey questions did not improve significantly following the simulation, 1 each representing the cognitive and affective domains. The lack of significant change in these elements in the group as a whole may reflect a curriculum that is strong in those elements, since all groups reported improvement.

The results of this study indicate that students' self-perceived knowledge and skill levels increased whether the students participated in the role of a victim or the provider. It is clear that the potential exists for significant learning to occur with well-designed and concise simulation activities, regardless of the role students undertake.

\subsection{Limitations}

Several limitations to the study exist. The convenience sample consisted of students at one institution who were primarily women and may not be representative of students at other institutions, thus impacting generalizability of the results. Three separate class sections participated in the simulation over a year, and three faculty members taught different pieces of the lecture. It is possible that the variations in time, faculty and teaching methods could have influenced the results. Also, faculty members could have influenced the content of the didactic portion to enhance success, and injected bias in selecting students for various roles based on their relationship with the students. However, simulation is designed to provide active learning in order to reinforce classroom content. ${ }^{[23]}$ Additionally, identifying and utilizing the strengths of students to play various roles is a purposeful instructional strategy. 
This study relied on self-reported data rather than concrete measures of knowledge, attitude and skills. It can be argued that positive self-perception is important to students and thus worth measuring. In the future, it would be interesting to correlate positive self-perception with performance. Finally, the survey instrument was new and had yet to be used with or tested for, the target population. In the future, it would be edited to reflect actual knowledge gain and self-confidence using a validated scale. ${ }^{[26]}$

\section{Conclusion}

As the frequency and strength of disasters increase, nursing students should be trained to respond to complement their future professional practice. ${ }^{[4]} \mathrm{MCI}$ simulation is a valuable tool in educating traditional and non-traditional nursing students alike. It assists in transferring passive learning in the classroom into experiences that mimic real life. ${ }^{[23]}$ It can be designed to reinforce cognitive, affective and psychomotor learning and should be structured to move students along the novice-to-expert continuum ${ }^{[7]}$ in mastering the ICN disaster management competencies. ${ }^{[6]}$ It does not need to include large numbers of participants or high fidelity manikins to be effective and can be easily incorporated into nursing curricula. Additionally, learning can occur regardless of the role students undertake. Suggestions for future research are to include students from other health-related professions and a more diverse student population in the scenario. Also, criteria for demonstrating knowledge, and skill improvement should be developed and assessed, and self-confidence scales should be adapted to this topic.

\section{CONFlicts of InTEREST Disclosure}

The authors declare that there is no conflict of interest.

\section{REFERENCES}

[1] Ranse J, Lenson S. Beyond a clinical role: Nurses were psychosocial supporters, coordinators and problem solvers in the Black Satusrday and Victorian bushfires in 2009. Australasian Emergency Nursing Journal. 2012; 15: 156-163. PMid:22947688 http://dx. doi .org $/ 10.1016 / j$.aenj.2012.05.001

[2] Baack S, Alfred D. Nurses' preparedness and perceived competence in managing disasters. Journal of Nursing Scholarship. 2013; 45(3): 281-287. http://dx.doi.org/10.1111/jnu. 12029

[3] Chaffee M. Willingness of health care personnel to work in a disaster: an integrative review of the literature. Disaster Medicine and Public Health Preparedness. 2009; 3: 42-56. PMid:19293743 http://dx.doi.org/10.1097/DMP. 0b013e31818e8934

[4] American Association of Colleges of Nursing. The essentials of baccalaureate education for professional nursing practice. Washington DC: 2008 .

[5] Schmidt CK, Davis JM, Sanders JL, et al. Exploring nursing students' level of preparedness for disaster response. Nursing Education Perspectives. 2011; 32(4): 380-383. PMid:22235694 http: //dx.doi.org/10.5480/1536-5026-32.6.380

[6] International Council of Nurses of the World Health Organization. ICN Framework of Disaster Nursing Competencies. 2009.

[7] Benner P. From novice to expert. American Journal of Nursing. 1982; 82: 402-407. PMid:6917683

[8] Carter MR, Gaskins SW. Incorporating bioterrorism content in the nursing curriculum: A creative approach. Journal of Nursing Education. 2010; 49(7): 406-409. PMid:20210283 http://dx. doi .org /10.3928/01484834-20100217-08

[9] Ireland M, Ea E, Kontzamanis E, et al. Integrating disaster preparedness into a community health nursing course: One school's experience. Disaster Management and Response. 2006; 4(3): 7276. PMid:16904616 http://dx.doi.org/10.1016/j.dmr. 200 6.03 .001

[10] Kuntz SW, Frable P, Qureshi K, et al. Association of community health nursing educators: Disaster preparedenss white paper for Community/Public health nursing educators. Public Health Nursing.
2008; 25(4): 362-369. PMid:18666942 http://dx.doi.org/10. $1111 / j .1525-1446.2008 .00717 . x$

[11] Atack L, Parker K, Rocchi M, et al. The impact of an online interprofessional course in disaster management competency and attitude towards interprofessional learning. Journal of Interprofessional Care. 2009; 23(6): 586-598. PMid:19842952 http://dx.doi.org/10. $3109 / 13561820902886238$

[12] Hutchinson SW, Haynes S, Parke P, et al. Implementing a multidisciplinary disaster simulation for undergraduate nursing students. Nursing Education Perspectives. 2011; 32(4): 240-243. http: //dx.doi.org/10.5480/1536-5026-32.4.240

[13] Morrison AM, Catanzaro AM. High-fidelity simulation and emergency preparedness. Public Health Nursing. 2010; 27(2): 164 173. PMid:20433671 http://dx.doi.org/10.1111/j.1525-1 $446.2010 .00838 . x$

[14] Shannon CC. Using a simulated mass casualty incident to teach response readiness: a case study. Journal of Nursing Education. 2015; 54(4): 215-219. PMid:25826762 http://dx.doi.org/10.3928 101484834-20150318-05

[15] Kaplan BG, Connor A, Ferranti EP, et al. Use of an emergency preparedness disaster simulation with undergraduate nursing students. Public Health Nursing. 2012; 29(1): 44-51. PMid:22211751 http://dx.doi.org/10.1111/j.1525-1446.2011.00960.x

[16] Pang SM, Chan SS, Cheng Y. Pilot training program for developing disaster nursing competencies among undergraduate students in China. Nursing and Health Sciences. 2009; 11(4): 367-373. PMid:19909443 http://dx.doi.org/10.1111/j.1442-2018.2009.00499.x

[17] Chan SS, Chan W, Cheng Y, et al. Development and evaluation of an undergraduate training course for developing International Council of Nurses Disaster Nursing Competencies in China. Journal of Nursing Scholarship. 2010; 42(4): 405-413. PMid:21091623 http://dx.doi.org/10.1111/j.1547-5069.2010.01363.x

[18] Farra S, Miller E, Timm N, et al. Improved training for disasters using 3-D virtual reality simulation. Western Journal of Nursing Research. 2013; 35(5): 655-671. PMid:23287551 http://dx.doi.o $\mathrm{rg} / 10.1177 / 0193945912471735$ 
[19] Landry LG, Stockton A. Evaluation of a collaborative project in disaster preparedness. Nurse Educator. 2008; 33(6): 254 258. PMid:18981905 http://dx.doi.org/10.1097/01.NNE.00 $00334786.15052 . \mathrm{d} 9$

[20] US Department of Labor. Incident Command System (ICS) ETool. n.d. https://www.osha.gov/SLTC/etools/ics/what_ is_ics.html

[21] US Department of Health and Human Services. Chemical Hazards Emergency Medical Management. START Adult Triage Algorithm. 2014.

[22] Mayville M. Debriefing: the essential step in simulation. Neonatal and Infant Nursing Reviews. 2011; 11(1): 35-39. http://dx.doi .org/10.1053/j.nainr.2010.12.012
[23] Durham C, Alden K. Enhancing patient safety in nursing education through patient education. In Hughes RD (Ed). Patient safety and quality: an evidence-based handbook for nurses (Chapter 51). Rockville, MD: Agency for Health Care Research and Quality. 2008

[24] Cedarbaum J, Klusaritz H. Clinical instruction: using the strengthsbased approach with nursing students. Journal of Nursing Education. 2009; 48: 422-428. http://dx.doi.org/10.3928/01484834-2 0090518-01

[25] Meakim C, Barrow MA. Clinical simulation in nursing education. National School Nurses Association Imprint. 2009; 40-42. PMid:19514218

[26] White K. Development and validation of a tool to measure selfconfidence and anxiety in nursing students during clinical decision making. Journal of Nursing Education. 2014; 53(1): 14-22. PMid:24256004 